Please do not remove this page

RMIT

UNIVERSITY

\title{
Local action to support knowledge-based development
}

Badenhorst, Anne; Scarf, Charlotte

https://researchrepository.rmit.edu.au/esploro/outputs/9921858473601341/filesAndLinks?institution=61RMIT_INST\&index=null

Badenhorst, A., \& Scarf, C. (2011). Local action to support knowledge-based development. International Journal of Knowledge-Based Development, 2(3), 316-333. https://doi.org/10.1504/IJKBD.2011.042524

Document Version: Accepted Manuscript

Published Version: https://doi.org/10.1504/JJKBD.2011.042524

Repository homepage: https://researchrepository.rmit.edu.au

Copyright (C) 2011 Inderscience Enterprises Ltd

Downloaded On 2023/04/26 16:00:32 +1000

Please do not remove this page 
Thank you for downloading this document from the RMIT Research Repository.

The RMIT Research Repository is an open access database showcasing the research outputs of RMIT University researchers.

RMIT Research Repository: http://researchbank.rmit.edu.au/

\section{Citation: \\ Badenhorst, A and Scarf, C 2011, 'Local action to support knowledge-based development', International Journal of Knowledge-Based Development, vol. 2, no. 3, pp. 316-333.}

See this record in the RMIT Research Repository at:

https://researchbank.rmit.edu.au/view/rmit:12516

Version: Accepted Manuscript

Copyright Statement:

(C) 2011 Inderscience Enterprises Ltd

Link to Published Version:

https://doi.org/10.1504/IJKBD.2011.042524 
72

\title{
Local action to support knowledge-based urban development: learning from Melbourne's north
}

\author{
Anne Badenhorst * \\ Badenhorst \& Associates \\ Email: anne.badenhorst@optusnet.com.au \\ Charlotte Scarf \\ School of Global Studies, Social Science and Planning \\ RMIT University \\ E-mail: charlotte.scarf@rmit.edu.au \\ * Corresponding author
}

\begin{abstract}
The purpose of this paper is to elaborate on a conceptual toolkit to support understanding and offer assistance to community leaders and policymakers to plan Knowledge Cities based around existing efforts to support learning in localised settings. We start with a conceptual framework that was applied to a regional development program in the Northern metropolitan region of Melbourne, Australia. In setting out the key features of a learning region, we show how the framework supports the identification of policy gaps and program needs, drawing on case data from Melbourne's North. Despite the limitations exposed by the study, the analysis reveals that there can be significant local action to support learning that contributes to the broader goals of Knowledge Cities that leverages but is not entirely reliant on external support. We conceptualise this local action using Wenger's (2002) 'infrastructures of learning' framework. Whilst conceptually useful for researchers, we recognise the limitations of this approach for policy and program planning in the absence of detailed case data. We thus conclude the paper by highlighting a network-mapping tool that may assist in the identification of local infrastructures of learning in the absence of detailed case data.
\end{abstract}

Keywords - urban development, learning regions, conceptual toolkit, communities of practice, learning infrastructures

Paper type - Academic Research Paper / Practical Paper

\section{Introduction}

The combination of post-industrial urbanisation, coupled with the transition from material-based to knowledge-based production has given rise to new policy and research communities centred around the concepts of 'Knowledge Cities' and 'Learning Regions'. While interest in these fields is growing rapidly, there is little consensus on appropriate conceptual frameworks for distinguishing the value of these phenomena from conventional urban planning and development (Carrillo 2006). Drawing on Carrillo (2006; 2009), we conceptualise the defining feature of Knowledge Cities as following from the realisation that conventional economic growth theory fails to account for the most distinctive dimensions of knowledge-based urban development; that is deliberate 
and informed societal transformation based on the capacity to learn and adapt to new challenges. This implies that Knowledge Cities need to be viewed in the widest possible terms. To facilitate their development, policymakers require holistic strategies that reflect social norms and relationships, as well as economic objectives. Putnam (2001) and Fukuyama (1995), among others, describe these elements as the social glue on which stable liberal democracies depend for economic growth. As a corollary, there is a 'possibility of a particularly resilient form of urban development secured in a network of connections anchored at local, national, and global coordinates' (Yigitcanlar 2007:5). Many scholars of knowledge-based development emphasise the importance of networks and clusters for fostering innovation (e.g. Lamboy 2006). The latter term, popularised by Porter (1990) was originally used to describe the spatial agglomeration of firms in specialised industries, but has since evolved to represent networks spanning multiple industries, sectors and regions (Belussi \& Sammarra 2010). It consistently refers to interconnected organisations, offering valuable opportunities for learning. Numerous urban and regional authorities have pursued policies designed to enhance innovation through the establishment of spatially defined networks and clusters. Most such strategies focus on enhancing cooperation between local industries, education institutions and government authorities, but some aim to promote high-tech clusters (Lamboy 2006). The current fashion is to foster the growth of the 'creative class' (Florida 2003). The City of Melbourne 2010 plan exemplifies these trends. It outlines the city's goals to become a Knowledge City by promoting education services, culture and creativity, becoming the ICT capital of Australia, and a gateway for biotechnology in the Asia Pacific, among other things (Cited in K. Ergazakis et al. 2004:12-13).

Many urban centres have become self-proclaimed Knowledge Cities based on these sorts of strategies. As yet, however, there is no coherent framework or unified methodology for guiding the design and implementation of successful Knowledge Cities (K. Ergazakis et al. 2006:3). Instead, there are on offer numerous conceptual frameworks that are intended to describe their characteristics and propose useful pathways to Knowledge City formation, based on comparative studies of major urban centres (e.g. Charles 2007, E. Ergazakis et al. 2009; K. Ergazakis et al. 2004, 2006). In this paper, we take a different approach. We elaborate on a conceptual toolkit that supports understanding and offers assistance to community leaders and policymakers to better target policy and program support for learning in localised settings. Drawing on an empirical investigation of a regional economic development program in the northern metropolitan region of Melbourne, we argue that greater understanding of how locallyembedded actors are linking and coordinating their activities to learn and adapt to change is needed to ensure that future efforts better address local needs and leverage local knowledge.

\section{Case study}

\subsection{Research context}

The empirical investigation that we focus on in this paper was framed by a larger international research project called, 'City Regions Intelligent Territories; Inclusiveness, Competitiveness and Learning' (CRITICAL). The CRITICAL Project was funded by the European Commission's Fifth Framework Programme for Research and Development, which covered a three-year period beginning in February 2003. It aimed to build understanding of learning processes within major urban centres by examining a range of 
formal and informal networks within which learning and knowledge development took place. One of the networks studied by the CRITICAL Project was an industry network based in the Northern metropolitan region of Melbourne, Australia. Our research grows from work undertaken in that context.

\subsection{Theoretical framework}

The CRITICAL project adopted Etienne Wenger's concept of the 'community of practice' (CoP) to identify formal and informal networks that function as potential sites of learning. A community of practice is broadly understood as 'a group of people who share a concern, a set of problems, or a passion about a topic, deepen their knowledge and expertise in this area by interacting on an ongoing basis' (Wenger et al. 2002:4). Wenger (1998) describes the structure of a CoP as consisting of three interrelated concepts: 'mutual engagement', 'joint enterprise' and 'shared repertoire' (Wenger 1998:72-73). Mutual engagement refers to the social norms and relationships that bind members together. Joint enterprise refers to their shared understanding of these norms and relationships. Shared repertoire refers to communal resources that members use in pursuit of their joint enterprise. All of these concepts hinge on the negotiation of meaning among members, which in Wenger's model consists of two interrelated concepts: 'reification' and 'participation'. Reification is essential for mutual understanding. It involves taking abstract understandings and turning them into concrete forms, such as documents. Participation involves translating and recontextualising shared understandings through practice. Crucially, Wenger describes the relationship between reification and participation as a dialectical one; he calls their successful interaction the 'alignment' of members' understandings and actions with their joint enterprise.

The CRITICAL Project placed strong priority on reification as a defining feature of the potential for learning in networks. This often played out with some tension in relation to participation in line with Wenger's theory. Importantly however, networks that were identified as communities of practice by the CRITICAL project consistently exhibited strong communal ownership as well as a shared repertoire of 'routines, words, tools ways of doing things, stories, gestures, symbols, genres, actions or concepts that the community has adapted in the course of its existence' (Wenger 1998:83). Participants in these communities of practice, expressed a clear sense of belonging to a joint enterprise that provided opportunities for learning through cooperation with participants from different organisations and sectors, but this was not necessarily expressed as a 'warm fuzzy' experience as the term 'community' might suggest. On the contrary, communities of practice were often found among project partners from different organisations and sectors where the negotiation of meaning was often a conflictual process.

\subsection{Methods}

The starting point for our study was an examination of the industry network in Melbourne's North. The communities of practice framework revealed numerous joint projects in which members of the industry network partnered with other locallyembedded actors outside the network. This led to an understanding of a regional economic development program in which the industry network played a central role in conjunction with another organisation. The first phase of our study thus involved an extensive literature review and examination of archives and documentation from organisations involved in the regional economic development program. Interviews were held with representatives of these organisations and relevant outsider groups in 2007- 
2008. The interviews were open ended and sought to understand the participants' experience of learning in the industry network and where other communities of practice might exist. A conceptual framework developed in the CRITICAL project was then used to categorise the data collected to assess the extent to which the Northern metropolitan region could be considered a learning region.

\section{The northern metropolitan region of Melbourne}

There is a rich history of regional economic development efforts in the Northern metropolitan region of Melbourne dating back more than 20 years. Our focus is on projects initiated between 2002-2008 by Northlink/NIETL and the Northern Area Consultative Committee (NACC which has since been replaced by the Northern Melbourne Regional Development Australia Committee or NMRDA). NorthLink/NIETL is a 'regional partnership of industry, education and government established for the purposes of economic development, regional marketing and promotion of Melbourne's North' (NorthLink/NIETL 2010). Its key focus is on supporting manufacturing and business development as an industry network of small-to-medium enterprises (SMEs), which it combines with a broader regional development role. The NACC was a federally funded regional development program that was operational from 1993-2009. Its charter changed over that period, moving from developing employment opportunities to a broader regional planning and development focus. The current federally funded NMRDA initiative has continuity with the broader goals of the NACC.

Northlink/NIETL and the NACC produced numerous publications over the course of the regional economic development program. Most notably, they produced an economic development plan in 2002, entitled 'Growing Melbourne’s North'. In 2009, the plan was updated and renamed, 'Melbourne’s North - the New Knowledge Economy'. The new report describes the region as characterised by diversity. It has a resident population from a broad range of cultural, educational and ethnic backgrounds, and old and new suburbs offering different levels of amenity. "Inner areas are moving rapidly towards a knowledge economy and creative development at the same time as manufacturing, logistics and warehousing activities continue to develop in the outer parts of the region" (NIEIR 2009:v). The largest employing industry is a declining manufacturing sector, followed by retail; health and community services; construction; and property and business services (ABS 2006 cited in NMRDA 2010). The inner areas of the region have faced challenges in 'developing an environment for new employment options to flourish and managing future residential densities' and the outer growth areas have faced challenges with 'high susceptibility to change and economic stress as a result of higher unemployment, low skill levels and managing the rural interface with Melbourne’ (Shepherd 2003:14).

The current regional economic development plan identifies as key, opportunities for:

- increased advanced manufacturing and development of industry clusters;

- $\quad$ greater integration between tertiary institutions and business for R\&D;

- $\quad$ attracting more knowledge intensive industries;

- $\quad$ up-skilling and retraining of workers;

- $\quad$ strategic development of Activity Centres and Central Activity Districts;

- increasing the number of business incubators; and the

- development of quality and sustainable communities and workplaces built to the highest design and environmental standards (NIEIR 2009). 


\section{The learning region in Melbourne's north}

\subsection{Conceptual framework}

The challenges faced by Melbourne's North highlight the need for federal and state government policies and programs to assist the region to learn and adapt to change. The extent to which the existing policy framework supported the region in this way was assessed using a conceptual framework developed by Charles (2006) in the CRITICAL Project. In this framework, the ideal Knowledge City / Learning Region is conceptualised as a combination of four pillars or subsystems of learning (See figure 1). Crucially, the four subsystems overlap and some actors are involved in more than one area. Indeed, 'bridge builders' or interlocutors are considered vital for learning to take place (Charles 2006:21). This underscores one of the major limitations of the framework, which like many conceptual tools that are intended to describe the key characteristics or set out pathways to Knowledge City formation: it fails to assist in the identification of bridge builders that support learning between categories. We will return to this point after we elaborate on our application of the framework to our study of Melbourne's North.

\begin{tabular}{|l|l|} 
1. The Learning Cooperative & 2. The Learning Cluster \\
$\begin{array}{l}\text { Development of learning and skills } \\
\text { improvement among citizens and local } \\
\text { labour force }\end{array}$ & $\begin{array}{l}\text { Promotion of clustering of local small to } \\
\text { medium enterprises (SMEs) and support } \\
\text { agencies }\end{array}$ \\
\hline $\begin{array}{l}\text { 3. The Learning District } \\
\begin{array}{l}\text { Formation of strategic alliances among } \\
\text { local R\&D establishments }\end{array}\end{array}$ & $\begin{array}{l}\text { 4. The Learning Network } \\
\text { Co-ordination of urban development } \\
\text { activities }\end{array}$ \\
\hline
\end{tabular}

Figure 1. The four pillars of learning

\subsubsection{The Learning Cooperative}

It is in the category of the Learning Co-operative that we found the northern metropolitan region of Melbourne had the strongest performance. This was largely due to the strong presence of education institutions in the region, and their willingness to work with local industry partners to address skills shortages through their involvement in the regional economic development program. NorthLink/NIETL and the NACC were highly effective at marshalling support from education institutions to leverage state and federal government programs to improve learning and skills development among residents. They also initiated and funded numerous projects, partnering with education institutions that provided in-kind support. There was widespread support for vocational education and training programs that targeted specific community groups, with access and equity being a clear priority. This was framed by consideration of employment opportunities, industry needs, the imperative to be competitive in the global marketplace.

NorthLink/NEITL and the NACC played an important role in taking advantage of state-funded programs to support this focus, with the Local Learning and Employment Network (LLEN) initiative being particularly well aligned with local priorities. The state government established the LLEN initiative in 2001 with the aim to improve education, training and employment options for young people aged 10-19 years and to foster the creation of sustainable relationships, partnerships and brokerage of initiatives with and 
across local education providers, industry and community (DEECD 2010). Our research found considerable crossover in the membership and projects of the three LLENs in Melbourne's North and the regional development program of Northlink/NEITL and NACC. There were formal connections through board and committee membership and joint projects, as well as less formal connections through networks and participation in projects and events.

Notable crossover projects include an initiative led by the NACC that brought TAFE and undergraduate courses into community centres targeting unemployed and disadvantaged learners, which was supported through partnerships with local companies and philanthropic organisations that fitted the centres with computers to assist learners seeking employment, and parents interested in supporting their children's learning (Career Connections, 2006). Another project saw postgraduate business and marketing students from LaTrobe University working with local enterprises on real-world problems. With funding from the Australian Greenhouse Office, NorthLink/NIETL developed a joint project with RMIT University through which students advised local businesses on ways to reduce their greenhouse gas emissions, identified the costs associated with implementing changes and the payback period (Greenhouse Office 2006). Meanwhile, the NACC led the development of funding proposals for a social enterprise to provide training and employment to people with disabilities; a community facility and access programs for migrant groups; coordination of aged care employment for ethnic communities; and projects aimed at improving indigenous employment outcomes (DOTARS 2006).

Also evident was strong support for developing pathways. Here, the NACC played a leading role in partnership with RMIT University and the local government of the City of Whittlesea in engaging local partners in an exemplar project, the Whittlesea Youth Commitment. This project brought together community organisations, local enterprises, and the Dusseldorp Skills Forum to ensure that early school leavers in that local government area were supported with pathways to vocational education, training or employment (DSF 2009). The Dussesdorp Skills Forum, a national body very active and respected in the discussion on training, skills development and young people first proposed the Youth Commitment model for Australia in 1999 (Speirings, 1999). The Whittlesea Youth Commitment was nationally recognised for its success, both in terms of its model of operations and in sustaining community engagement (Kellock 2001). Also initiated by the NACC and NorthLink/NIETL in partnership with RMIT University and Northern Metropolitan TAFE was the Northern Stainless Steel Skills Development Group. It was made up of representatives of local industry and education institutions and sought to address local skills shortages in that industry sector through the promotion of careers and provision of training programs in partnership with TAFE. The two lead organisations in the regional economic development program also provided machinery, in-kind and dollar support for the Northern Technology Education Centre at Northlands Secondary College (NACC 2004).

Northlands Secondary College enjoyed strong support from the NACC and NorthLINK/NIETL to provide technical training and become a Technology Education Centre for the region. Its priority was to offer 'engineering, manufacturing, auto electro technology, furnishing and horticulture courses, with equipment provided by industry sponsors' and to be the 'lead in a cluster working in partnership with the State Department of Education to establish a senior campus for secondary students seeking specialist maths/science training' (Northlands Secondary College 2006). Another example of this collaborative approach to supporting skills development and career pathways was 
the federally-funded Northern Schools VET cluster, which was also supported by NACC and NorthLINK/NIETL. It aided synergies between different organisations and sectors by coordinating the development of secondary school programs that sought to match the needs of the region, 'enable greater choice for students and reduce duplication in schools' (Career Connections 2006).

\subsubsection{The Learning Cluster}

We found some elements of the Learning Cluster in the northern metropolitan region of Melbourne, but the bulk of SME networking activity centred on Northlink/NEITL's membership base and was highly generalised in nature. NORTHlink/NIETL promoted SME networking across industry sectors through regular breakfasts and tours for its 2,000 odd members. Representation at these events was fairly consistent, with anywhere from 80 to 160 members attending breakfasts, and tours typically booked out within three weeks of their announcement. Members also participated in state and federal industry programs, which featured prominently at breakfasts where programs were often promoted using local enterprises as case studies (NORTH Link/NIETL 2006). The industry network also ran a federally funded Trade Start program for members. By 2007, 115 companies had achieved their export targets through the program, which was awarded additional resources and renewed funding contracts.

At the time of this research, a food manufacturing cluster was in the early stages of development in the region. There are also some examples of past 'clustering' initiatives such as an automotive project which focused on implementation of quality systems for suppliers to the automotive industry. This suggests that more targeted support is needed to build local SME capacity for innovation, potentially by strengthening the as yet limited opportunities for clustering by industry sector.

\subsubsection{The Learning District}

Despite strong university engagement with industry partners outside the region, we found little evidence of a Learning District in Melbourne's North. A key barrier to university interest in building equivalent patterns of linkages with local industry partners was the predominance of SMEs in the region and the lack of head offices of larger companies. Importantly, however, NorthLink/NIETL exerted little influence over this category of the learning region, which also helps to explain the region's lack lustre performance.

The two universities based in the region - RMIT and LaTrobe - each have a history of successful industry engagement through research and consultancy projects. However, relevant activity in Melbourne's North consisted primarily of teaching and learning activities and community outreach programs where students provided the resource or universities provided in-kind support. NorthLink/NIETL brokered many such projects, which ranged from postgraduate students undertaking research with local enterprises, to larger projects like the 'Greenhouse Challenge Plus Support' discussed in the Learning Cooperative section. Some projects involved local government, such as the Whittlesea Chinese herb garden project, where RMIT provided research support and Northern TAFE provided horticulture expertise to assess the feasibility of growing Chinese herbs. Both universities supported a NORTHLink/NIETL and NACC bid for funding to establish two business incubators in the region, but these were general business incubators with no specific technology focus. LaTrobe University has a business incubator and technology park on campus, which does provide technology and commercialisation support to industry, but lacks a local focus. 


\subsubsection{The Learning Network}

We found strong evidence of a vibrant Learning Network in Melbourne's North. This centred on NORTHlink/NIETL and the NACC, which each supported a wide range of networks that linked different organisations and sectors through the regional economic development program. For example, the NACC established the Economic Development Working Group, which included senior officials from all seven local government areas in Melbourne's North. This strengthened the linkages between the local governments, which in turn resulted in new support for collaborative projects. The Working Group produced two other outcomes of note. The first was a research project taken up by NORTHLink/NIETL, which sought to identify factors limiting the supply of commercial office space. The findings were presented to local government authorities to inform new planning and zoning policies (Australian Research Group \& SGS, 2007). The second was a cultural tourism project, which promoted cultural attractions in the region (NACC 2006). NORTHLink/NIETL and the NACC also initiated biannual briefings to local members of parliament to support better understanding of the region as a whole.

Complementing these initiatives were efforts by the two lead organisations to promote advocacy through the provision of research reports and project documentation to the local media. However, neither organisation had the capacity to build a substantive online presence to disseminate this information or support community engagement. As a corollary, the Learning Network in Melbourne's North was decidedly local and spatially bounded. It was not engaged with other regions across the city, let alone beyond this.

\section{Supporting learning}

Our analysis indicates that the nascent learning region in Melbourne's North depended a great deal on state and federal government programs, but it was not entirely dependent on them. State and federal government programs were enhanced by the substantial support for learning provided by NorthLink/NIETL and the NACC. These organisations were able to generate significant outcomes though their role as bridge builders between different categories of learning, despite the obvious limitations of the region's performance in each area that our study exposed.

In conceptualising the support for learning that these organisations provided, we return to Wenger who theorises that it is possible to 'cultivate' communities of practice (2002). In his model, communities of practice require a soft 'infrastructure' which enables people to 'engage, imagine and align' their practice (1998:237). Engagement can be supported by physical and virtual spaces, ways of belonging and opportunities to apply skills, develop tools and generate memory or history of the group (Wenger 1998:237). Imagination can be supported by 'orientation in space and time, opportunities for reflection and exploration' (Wenger 1998:238). Alignment can be supported by 'leadership, coordination, information transmission and such things as contracts, due process and policy' (Wenger 1998:238) We contend that NorthLink/NIETL and the NACC, provided this 'soft infrastructure' by utilising their local knowledge, position and networks to initiate projects, recruit partners, manage implementation and provide administrative support (See Table 1).

Projects grew out of spaces created by the lead organisations to generate interest and recruit potential partners in the regional economic development program. They supported imagination through research projects intended to identify opportunities and challenges in the region, solve problems and adapt to changes. They supported alignment through a shared model for projects aligned to their economic development plan. They also played an important brokering role by developing proposals, drawing up legal contracts and 
accepting and managing funds on behalf of other locally embedded actors. They produced publications to communicate project activity and to demonstrate capability in the region. These local actions allowed for cooperation at different levels and degrees and supported the collaborative exploration and 'envisioning possible futures' by local government agencies, education institutions, industry representatives and community groups in the region.

Table I. Infrastructures of learning

\begin{tabular}{|c|c|c|}
\hline Infrastructure & Definition & Examples \\
\hline \multirow[t]{3}{*}{ Engagement } & $\begin{array}{l}\text { - Physical and virtual } \\
\text { spaces } \\
\text { - Joint tasks } \\
\text { - Availability of help } \\
\text { - Boundary encounters: } \\
\text { ways of belonging to } \\
\text { different degrees, e.g. } \\
\text { casual encounters }\end{array}$ & $\begin{array}{l}\text { - Public forums and open meetings engaging } \\
\text { mixed audiences and targeted stakeholders } \\
\text { e.g. networks across sectors } \\
\text { - Forums/meetings organised with different } \\
\text { stakeholders at venues throughout the region } \\
\text { - Working groups/meetings with meeting } \\
\text { spaces, administrative support organised } \\
\text { - Options to participate in project working } \\
\text { groups, management committees, forums, } \\
\text { events or other general network activities } \\
\text { - Professional development and training } \\
\text { - Induction of new members }\end{array}$ \\
\hline & $\begin{array}{l}\text { - Problems that engage } \\
\text { energy, creativity and } \\
\text { inventiveness, }\end{array}$ & $\begin{array}{l}\text { - Current issues presented to local stakeholders } \\
\text { - Issues researched and documented with } \\
\text { attention to local data and impact } \\
\text { - Presentation of government policy, } \\
\text { background materials by relevant stakeholders } \\
\text { - Media and communications strategies }\end{array}$ \\
\hline & $\begin{array}{l}\text { - Reification } \\
\text { - Repositories of } \\
\text { information, } \\
\text { documentation }\end{array}$ & $\begin{array}{l}\text { - Regional Strategic Plans } \\
\text { - Regional publications } \\
\text { - Contacts databases } \\
\text { - Conference papers, presentations, launches, } \\
\text { events } \\
\text { - Outcomes from projects, e.g. common exit } \\
\text { form for early school leavers }\end{array}$ \\
\hline \multirow[t]{2}{*}{ Imagination } & - Location in space, time & $\begin{array}{l}\text { - Policy context of Australia and Victoria } \\
\text { - Regional data and local level statistics } \\
\text { - Mindful of stakeholder organisational } \\
\text { planning and operational cycles, e.g. school } \\
\text { year/financial year }\end{array}$ \\
\hline & $\begin{array}{l}\text { - Reflection } \\
\text { - Exploration }\end{array}$ & $\begin{array}{l}\text { - History of action documented, explained and } \\
\text { celebrated } \\
\text { - Discussion of issues to develop new projects } \\
\text { - Events to mark success or new activity } \\
\text { - Strategic planning through working groups } \\
\text { and project teams } \\
\text { - Expos, breakfasts, tours, events with speakers }\end{array}$ \\
\hline Alignment & $\begin{array}{l}\text { - Common focus } \\
\text { - Leadership } \\
\text { - Sources of inspiration }\end{array}$ & $\begin{array}{l}\text { - Leadership in context of regional } \\
\text { development } \\
\text { - Engagement of stakeholders and project } \\
\text { champions } \\
\text { - Distributed leadership by supporting project } \\
\text { champions } \\
\text { - Cross representation on boards }\end{array}$ \\
\hline
\end{tabular}




\begin{tabular}{|c|c|c|}
\hline Infrastructure & Definition & Examples \\
\hline & $\begin{array}{l}\text { - Standards and methods } \\
\text { - Processes, plans } \\
\text { - Communication } \\
\text { - Brokers }\end{array}$ & $\begin{array}{l}\text { - } \text { Management of stakeholders and } \\
\text { partnerships } \\
\text { - Explicit model for projects and project } \\
\text { management } \\
\text { - Strategic plans, project work plans } \\
\text { - Local media, PR, presentations } \\
\text { - } \text { Cross network support and activities }\end{array}$ \\
\hline & $\begin{array}{l}\text { - Policies, contracts, due } \\
\text { processes }\end{array}$ & $\begin{array}{l}\text { - Formal roles established in projects } \\
\text { - Meeting minutes } \\
\text { - } \text { Contracts with funding bodies, } \\
\text { - Financial and other administrative } \\
\text { relationships }\end{array}$ \\
\hline
\end{tabular}

\section{Envisioning infrastructures of learning}

The centrality of NORTHLink/NIETL and the NACC in supporting the infrastructures of learning in Melbourne's North was a key finding of our study. The education institutions also played a significant role, as is well documented in much research on knowledge-based urban development. Different roles however, highlight the need for practical tools to assist community leaders and policymakers in the identification of local focal points for learning to prevent insufficient support and/or duplication, particularly by state and federal governments when it comes to policy and program planning and development.

One such tool that could be useful in this context is a software program developed by the Amsterdam-based Govcom.org Foundation, called the 'IssueCrawler', which locates and visualises networks on the Web (http://www.issuecrawler.net). The application was originally designed to assist NGOs to identify networks of organisations that aggregate around a particular policy issue. It offers numerous relevant functions for community leaders and policymakers to plan Knowledge Cities based around existing efforts to support learning in localised settings, including the ability to identify a specific organisation's overall network, its centrality within a particular network, or the cluster it finds itself in. It can also show how a particular network has evolved over time, which groups have become more central and which less so, and whether the network has shifted geographically and/or in terms of focus.

The IssueCrawler is a much more powerful tool than conventional 'cluster mapping' programs, which map spatial agglomerations of interconnected firms, universities and R\&D establishments that arise out of linkages across industries, using employment statics from relevant public agencies (See the European Cluster Observatory of the Stockholm School of Economics: http://www.clusterobservatory.eu/; and the Cluster Mapping Project of Harvard Business School: http://data.isc.hbs.edu/cmp-nj/index.jsp). It communicates relationships between interconnected organisations by visualising hyperlinks from specified organisations' websites. Theoretically, it could enable the visualisation of organisations with links to the 2009 economic development plan, 'Melbourne's North - the New Knowledge Economy'. However, NORTHLink/NIETL and the NACC made poor use of the Web to demonstrate the capability of the region, and the report is not posted on any site where it would be possible to track these connections.

Interestingly, from a starting point of NorthLink/NIETL and the NACC, the IssueCrawler produces a network map of government sites (See Figure 2). The map thus depicts funding and information sources as the prominent network nodes in Melbourne's North, as organisations are sorted by the popularity of their websites. This may simply 
confirm the fact that many of the organisations in the region are regular seekers of funds and information from government, and possibly, given that the search was initiated from NorthLink/NIETL and the NACC, that these organisations have supported the effective leveraging of government programs by local industry. It is of course a significant finding that neither the NACC nor NorthLINK NIETL appear in the IssueCrawler map despite their central role in supporting learning in Melbourne's North, often independently of government funding. It lends further weight to our finding that the Learning Network category of the learning region was decidedly local and spatially bounded.

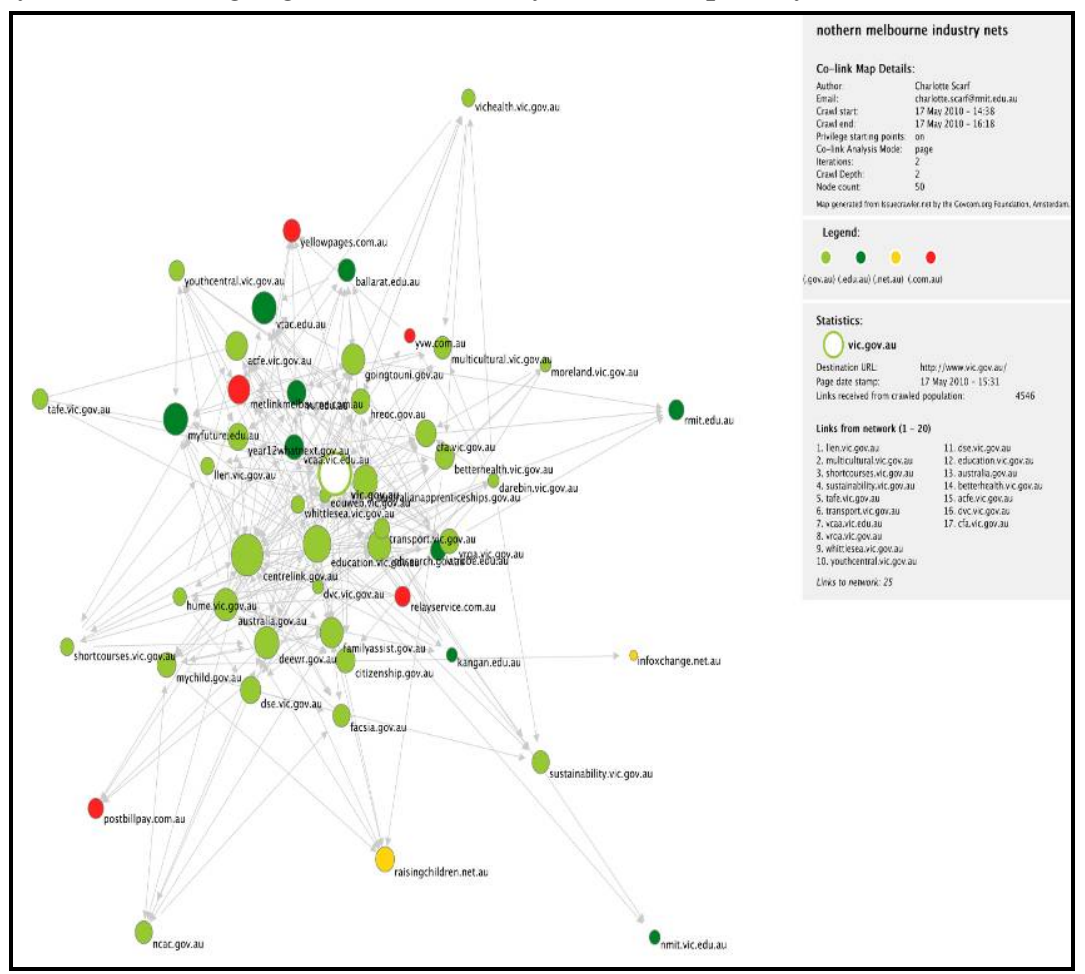

Figure 2. Inter-organisational networks in Melbourne’s north

Source: IssueCrawler 2010.

\section{Conclusion}

Building on the work of the CRITICAL project, this paper has outlined a conceptual toolkit to support understanding and offer assistance to community leaders and policymakers to plan Knowledge Cities based around existing efforts to support learning in localised settings. The toolkit relies on 'communities of practice' to conceptualise and analyse learning in localised settings, which can take a variety of forms. In our study of the northern metropolitan region of Melbourne, communities of practice were most often found among project partners in the regional economic development program of NorthLink/NEITL and the NACC. The next element of the toolkit is a conceptual framework developed by Charles (2006), which facilitates the categorisation of project activity in terms of its contribution to learning. In our case study, this analysis revealed that there can be significant local action that contributes to the broader goals of 
Knowledge Cities, which leverages but is not entirely dependent on external support, which was lacking in some areas. The final element of the toolkit includes the facilities of engagement, imagination and alignment conceptualised by Wenger. In our case study, this theory assisted in the identification of NorthLink/NEITL and the NACC as the principal bridge builders between different categories of learning in Melbourne's North.

NorthLink/NEITL and the NACC engaged locally embedded actors from different organisations and sectors, encouraged them to imagine possible futures, and aligned their perspectives and actions with a shared repertoire of tools, processes and documents, including an economic development plan. The centrality of their role underscores the need for greater understanding of how locally-embedded actors are linking and coordinating their activities to learn and adapt to change in order to ensure that future policies and programs better address local needs and leverage local knowledge. Education institutions clearly make an important contribution to this effort, but our analysis suggests that R\&D support should be closely examined and not assumed. In highlighting networkmapping software, we sought to offer an efficient way of identifying local focal points for learning, but effectiveness depends on Web presence. This raises interesting questions for policy and program planning and development in terms of how learning is fostered and knowledge is shared and disseminated in localised settings. While much of the research on knowledge-based urban development explores these questions in iconic 'Knowledge Cities', which are naturally complex and differ greatly, a great depth of knowledge is required to understand learning even in small localised areas of cities, as was demonstrated in this paper.

\section{References}

Australian Department of Transport and Regional Affairs (2006) Area Consultative Committees, accessed July 10, 2006, <http://www.acc.gov.au/index.aspx>.

Australian Research Group \& SGS Economics and Planning (2007) Northern Exposure: An Analysis of Office and Commercial Accommodation, North/Link NIETL, Melbourne.

Belussi, F. and Sammarra, A. (eds.) (2010) Business Networks in Clusters and Industrial Districts, New York: Routledge.

Carrillo, F, J. (2006) 'Introduction: The Century of Knowledge Cities' In F.J. Carrillo (ed.) Knowledge Citie: Approach, Experience and Perspective, Burlington, MA: Elsevier, pp. xi-xv.

Carrillo, F, J. (2009) Demarcation and levels of analysis in knowledge based development, Journal of Knowledge Management, 13(5), pp. 208-13.

Charles, D. (2006) City Regions Intelligent Territories; Inclusiveness, Competitiveness and Learning, Centre for Urban and Regional Development Studies, Newcastle University, UK.

Charles, D. (2007) City Regions Intelligent Territories; Inclusiveness, Competitiveness and Learning, Regions, The Voice of the Membership, Reg. Stu. Assoc. No. 267, Autumn pp. 3-21.

Career Connections (2006) November News, Accessed November 3, 2006, from <http: //www.careerconnectionsnortheast.com.au/>

Dusseldorp Skills Forum (2000) Youth Commitment, Whittlesea Manuals Resources and Story. Accessed May 20, 2010, from <http://www.dsf.org.au/resources/detail/?id=31>

Ergazakis,E, Ergazakis,K, Metaxiotis, K and Charalabidis, Y (2009) 'Rethinking the development of successful knowledge cities: an advanced framework', Journal of Knowledge Management, 13(5), pp. 214-227.

Ergazakis, K, Metaxiotis, K and Psarras, J (2006) 'An Emerging Pattern of Successful Knowledge Cities’ Main Features' In Francisco Javier Carrillo (ed.) Knowledge Cities: Approaches, Experiences and Perspectives, Burlington, MA: Elsevier pp. 3-30. 
Ergazakis, K, Metaxiotis, K, and Psarras, J (2004) 'Towards Knowledge Cities: Conceptual analysis and success stories’, Journal of Knowledge Management, 8(5), pp. 5-15.

European Cluster Observatory (2010) Accessed August 1, 2010, from $<$ http://www.clusterobservatory.eu/index.php?country_ID=\&cluster_ID=5>

Florida, R (2003) The Rise of the Creative Class, North Melbourne: Pluto Press.

Fukuyama, F (1995) Trust: The Social Virtues and the Creation of Prosperity. New York: Free Press

Greenhouse Office (2006) The Plus Factor. RMIT: Students Go Green. Issue 3, Australian Department of Environment and Water Resources, Accessed September 3, 2006, from $<$ http://www.greenhouse.gov.au>

Hume City Council (2006) Hume Media accessed November 12, 2006, from $<$ http://www.hume.vic.gov.au/>

Kellock, P. (2001) The Whittlesea Youth Commitment; A Review. Melbourne: The Asquith Group.

Lamboy, J. G. (2006) 'Knowledge Dissemination and Innovation in Urban Regions: An Evolutionary Perspective’, In Francisco Javier Carrillo (ed.) Knowledge Cities: Approaches, Experiences and Perspectives, Burlington, MA: Elsevier pp. 223-232

National Institute of Economic and Industry Research (NIEIR) (2009) Melbourne's North - the new knowledge economy, Coburg: NorthLink/NIETL.

Northern Area Consultative Committee \& NORTH Link/NIETL (2006) Growing Melbourne's North - Information Paper February 2006, Melbourne: NACC.

Northern Melbourne Regional Development Australia Committee (NMRDA) (2010) Business Plan, Regional Development Victoria/Regional Development Australia, Melbourne.

Northland Secondary College (2006) Annual Report, Accessed July 3, 2007, from $<$ http://www.northland.vic.edu.au/>

NorthLink/NIETL (2010) <http://www.melbournesnorth.com.au/about-us>

NORTH Link/NIETL (2006) Northern News, Accessed November 12, 2006, from $<$ http://www.melbournesnorth.com.au>

Porter, M. (1990) The Competitive Advantage of Nations. London: Macmillan.

Putman, R (2001) Bowling Alone: the collapse and revival of American community, London: Simon and Schuster.

Rivera-Vazquez, J.C., Ortiz-Fournier, L.V and Rogelio Flores, F (2009) Overcoming cultural barriers for innovation and knowledge sharing, Journal of Knowledge Management, 13(5), pp. 257-270.

Shepherd, C (2003) Growing Melbourne's North, Developing an Integrated Economy, Northern Area Consultative Committee. Accessed November 12, 2006, from $<$ http://www.northernacc.com/index.jsp>

Spierings, J. (1999) Why Australia Needs a National Youth Commitment. Accessed September 10, 2006, from < http://www.dsf.org.au/nyc/why.html>

Victorian Department of Education and Early Childhood Development. Local Learning and Employment Networks <http://www.llen.vic.gov.au/>

Wenger, E. (1998) Communities of Practice. Learning Meaning and Identity, Cambridge: Cambridge University Press.

Wenger, E., McDermott, R., Snyder, W.M. (2002) A guide to managing knowledge. Cultivating Communities of Practice. Boston: Harvard Business School Press.

Wickham,J. (2004) CRITICAL Notes. Centre for Urban and Regional Development Studies, Newcastle University, UK. Unpublished.

Yigitcanlar, Tan, A. (2007) The Making of urban Spaces for the Knowledge Economy: Global practices. In proceedings The 2nd International Symposium on Knowledge Cities: Future of Cities in the Knowledge Economy, Malaysia, pp. 73-97. 